\title{
Influence of preheating and post-curing on a novel fiber-reinforced composite post material
}

Letícia Nunes de ALMEIDA ${ }^{(a)}$ Gustavo Adolfo Martins MENDES(a) Isabella Negro FAVARÃO(a) Amanda Vessoni Barbosa KASUYA(b) Marcela Gonçalves BORGES(c) Murilo de Sousa MENEZES(c) Rodrigo Borges FONSECA(a)

(a) Universidade Federal de Goiás UFG, Dentistry School, Department of Restorative and Operative Dentistry, Goiânia, GO, Brazil.

(b) Universidade do Oeste Paulista - Unoeste, Department of Restorative and Operative Dentistry School, Presidente Prudente, SP, Brazil.

(c) Universidade Federal de Uberlândia - UFU, Dentistry School, Department of Restorative and Operative Dentistry, Uberlândia, MG, Brazil.

Declaration of Interests: The authors certify that they have no commercial or associative interest that represents a conflict of interest in connection with the manuscript.

Corresponding Author:

Letícia Nunes de Almeida

E-mail: leticia18odonto@gmail.com

hitps://doi.org/10.1590/1807-3107bor-2018.vol32.0097

Submitted: March 11, 2018

Accepted for publication: June 27, 2018

Last revision: August 13, 2018
Abstract: The aim of this study was to investigate the influence of preheating and post-curing methods on diametral tensile strength (DTS), flexural strength (FS), knoop microhardness (KHN), and degree of conversion (DC) of an experimental fiber-reinforced composite (FRC). Specimens (30 wt\% of 3-mm-short E-glass fiber, $22.5 \mathrm{wt} \%$ of methacrylated-based resin and $47.5 \mathrm{wt} \%$ of filler particles) were subjected to: $\mathrm{P}$ - photocuring at $1500 \mathrm{~mW} / \mathrm{cm} 2$ for $40 \mathrm{~s}$ (control); $\mathrm{P} / \mathrm{M}$ - photocuring and microwave post-curing (540W/5 minutes); $\mathrm{P} / \mathrm{A}$ - photocuring and autoclave post-curing $\left(120^{\circ} \mathrm{C} / 15\right.$ minutes); $\mathrm{PH}-\mathrm{P}$ - preheating $\left(60^{\circ} \mathrm{C}\right)$ and photocuring; $\mathrm{PH}-\mathrm{P} / \mathrm{M}$ - preheating, photocuring and microwave post-curing; and PH-P/A - preheating, photocuring and autoclave post-curing. Specimens for DTS $(\varnothing 3 \times 6 \mathrm{~mm})$ and FS $(25 \times 2 \times 2 \mathrm{~mm})$ were tested at Instron 5965. KHN employed a 50g load for 30s. DC was measured using FTIR spectroscopy. Statistical analysis employed: factorial analysis, normality test, one-way ANOVA and Tukey's HSD test, independent T-test and the Dunnett test. Interaction between factors was not significant $(\mathrm{P}>0.05)$. Preheating promoted significantly higher values of FS and KHN ( $p=0.0001)$. Post-curing promoted significantly higher values for KHN $(p=0.0001)$. For DTS $(p=0.066)$ and DC $(p=0.724)$ no statistical difference was found between groups. SEM images showed that preheating promoted better interaction between glass fibers and resin matrix. Preheating increased FS, KHN and DTS, and post-curing increased KHN. DC was not affected by both methods. Preheating and post-curing methods can be used to improve some mechanical properties of FRCs' but degree of conversion remains unaffected.

Keywords: Casts, Surgical.

\section{Introduction}

Recently, dentists have used fiber-reinforced composites (FRCs) ${ }^{1,2}$ to reinforce fixed partial dentures, ${ }^{3}$ and direct restorations, ${ }^{4}$ to produce intraradicular posts, ${ }^{5,6,7}$ to splint periodontally involved teeth and for orthodontic applications. ${ }^{8}$ FRCs were mainly developed to improve mechanical properties of resin composites, thereby extending their indications. ${ }^{4,9,10}$ The first-ever marketed FRC (everX Posterior; GC, Tokyo, Japan) aimed to mimic the elastic properties of dentin and was indicated as a bulk base in high stress-bearing areas. ${ }^{1}$ It comprised a resin matrix 
[bisphenol-A-diglycidyl-dimethacrylate (bis-GMA), triethylene glycol dimethacrylate (TEGDMA), and polymethylmethacrylate], randomly-orientated E-glass fibers, and inorganic particulate fillers. ${ }^{1}$ Formulation improvements might extend the indications of FRCs.

Garoushi, Vallittu, and Lassila ${ }^{9}$ created a FRC comprising $22.5 \mathrm{wt} \%$ of short glass fibers, $22.5 \mathrm{wt} \%$ of methacrylate-based resin, and $55 \mathrm{wt} \%$ of silanetreated silica filler, which showed better mechanical performance compared with conventional restorative composites. This formulation has been widely studied and is commercially available as everX (GC, Tokyo, Japan). Moreover, a novel FRC, with increased fiber content (up to $30 \mathrm{wt} \%$ ) in a different Bis-GMA/TEGDMA particle-filled resin matrix, showed improved diametral tensile strength (DTS) and flexural strength (FS) compared with the previouslymentioned composition. ${ }^{11}$ More research remains to be done since the authors' intent was to use the material to produce anatomic fiber posts.

Highly fiber-loaded FRCs tend to have regions of poorly impregnated fibers, thus introducing voids and defects at the fiber-matrix interface. These voids decrease the FRC's flexural properties; ${ }^{11}$ hence, techniques to increase the fiber content and simultaneously reduce internal flaws would be desirable. The effectiveness of fiber reinforcement depends on many variables, including the fiber quantity in the resin matrix ${ }^{11}$ and the fibers' length, ${ }^{12,13}$ shape, and orientation. ${ }^{13,14}$ Another important factor is the adhesion between the fibers and resin matrix, ${ }^{15}$ which enables stress transference between these two substrates. Silane-treated glass fibers have higher surface energy and tend to be better impregnated by polymers; ${ }^{16,17}$ however, the high fiber content results in reduction of impregnation efficiency. ${ }^{11}$ Without adequate adhesion, fibers act as a foreign body in the resin matrix, thus weakening the FRC. ${ }^{17}$ In addition, voids within the FRC create fracture spots, thereby breaking down the material. Therefore, the interaction between the fibers and resin matrix is fundamental to the mechanical performance and longevity of FRCs for restorative purposes. ${ }^{18,19}$

Conventional resin composites need to achieve high monomer conversion to yield stable polymers. ${ }^{20}$ Preheating resin composites reduces paste viscosity and enhances radical mobility, thus resulting in higher monomer conversion. ${ }^{21,22,23,24}$ Preheating composites decreases paste viscosity because thermal vibrations force monomers and oligomers further apart. This allows them to slide by each other, thus providing greater mobility for free radicals and increasing the collision frequency of nonreactive groups. ${ }^{25,26}$ Studies have shown that preheating resin composites up to $54^{\circ} \mathrm{C}$ or $60^{\circ} \mathrm{C}$ increases the degree of conversion (DC) and hardness..$^{24,25}$ Preheating FRCs should decrease the resin matrix viscosity, thus promoting better interaction between the fibers and resin and increasing mechanical properties and DC.

Adequate light-curing is another important factor affecting the clinical behavior of composites, ${ }^{27}$ and incomplete polymerization reactions are usually associated with poor physical and mechanical properties, higher solubility, susceptibility to abrasion, and poor color stability. ${ }^{28,29}$ Ideally, all of the monomers present in the resin composite should be polymerized; however, dimethacrylate monomers exhibit residual carbon double bonds in the final material. ${ }^{20}$ The polymerization reaction causes internal mobility restrictions within the growing polymer matrix, which, in turn, reduce the polymerization rate. Consequently, free radicals reduce their movement within the matrix such that the polymerization continues at a slower rate. ${ }^{20,29}$ Postcuring polymerization continues up to 24 hours after initial irradiation, and additional curing procedures have been proposed, including exposure to intense light, secondary heating (microwave and autoclave), and pressure application (autoclave).${ }^{30}$ Post-curing methods reportedly promote better mechanical properties and higher DC of conventional resin composites. ${ }^{29,30,31,32,33}$ Therefore, the mechanical properties of FRC and DC might benefit from post-curing methods.

Owing to the potential benefits of preheating and post-curing conventional resin composites, it is important to evaluate the mechanical properties and DC of FRCs treated using these methods. Thus, the aim of this study was to evaluate the effects of preheating and post-curing on the mechanical properties (DTS, FS, and knoop microhardness) 
and DC of an experimental FRC. Was hypothesized that preheating and post-curing methods could improve the physical and mechanical properties of the experimental FRC.

\section{Methodology}

\section{Experimental groups}

Materials, batch numbers, and manufacturers are listed in Table 1. Six experimental groups were created. FRCs in each group were exposed to different pre-polymerization composite temperatures (two levels: room temperature and $60^{\circ} \mathrm{C}$ ) and post-curing methods (three levels: none, microwave, or autoclave). The experimental groups are shown in Table 2.

\section{Experimental composite manipulation}

The experimental composite comprised $22.5 \mathrm{wt} \%$ of methacrylate-based resin, $47.5 \mathrm{wt} \%$ of filler particles $(\mathrm{BaAlSiO}$ glass; Esstech, Essington, USA), and $30 \mathrm{wt} \%$ of E-glass fibers with original dimensions (length/diameter) of $3 \mathrm{~mm} / 12 \mu \mathrm{m}$ (Owens Corning, Rio Claro, Brazil). The methacrylate-based resin mixture comprised 40\% Bis-GMA (Sigma-Aldrich, Saint Louis, USA) and 60\% TEGDMA (Sigma-Aldrich) in a photo-initiator system mode containing $1 \mathrm{~mol} \%$ of camphorquinone, $2 \mathrm{~mol} \%$ of dimethylaminoethyl methacrylate (DMAEMA; Sigma-Aldrich), and $0.1 \mathrm{~mol} \%$ of butylated hydroxytoluene (BHT) (Sigma-Aldrich), as described by Fonseca et al. ${ }^{11}$ All components were weighed on an analytical balance and mixed in a high-speed magnetic homogenizer.

Silanated $\mathrm{BaAlSiO}_{2}$ filler particles $(0.7-\mu \mathrm{m}$; Esstech, Essington, USA) were manually mixed into the resin until a visually homogeneous mixture was achieved. Glass fibers were subjected to surface treatment with a silane coupling agent (Angelus, Londrina, Brazil) before incorporation into the resin. For each $5 \mathrm{~g}$ of glass fiber, $8 \mathrm{~mL}$ of silane coupling agent was added in accordance with a previous pilot study. After fibers were wet with silane and stored at room temperature for 24 hours to allow for solvent evaporation and were then manually incorporated into the resin. Both filler particles and glass fibers were immediately weighed on an analytical balance prior to incorporation into the resin mixture.

Table 1. Materials used in this study.

\begin{tabular}{lcc}
\hline Material & Manufacturer & Batch \\
\hline Glass fiber & Owens Corning, Riberão Claro, Brazil & 3552 \\
Coupling agent (silane) & Angelus, Londrina, Brazil & 34013 \\
Condensation silicone impression material (Clonage) & Nova DFL, Rio de Janeiro, Brazil & 4579 \\
Silicone-carbide Sandpaper & Norton Abrasivos, Paris, France & $* *$ \\
BIS-GMA (2,2-bis ([4 - (2 - hydroxy-3-metilacriloxipropoxi) phenyl]-propane)) & Sigma-Aldrich, St. Louis, EUA & MKBK4290V \\
TEGDMA (triethylene glycol dimethacrylate) & Sigma-Aldrich, St. Louis, EUA & STBC51937 \\
Camphorquinone & Sigma-Aldrich, St. Louis, EUA & STBC7007V \\
DMAEMA (Dimethylaminoethyl methacrylate) & Sigma-Aldrich, St. Louis, EUA & BCBJ3899V \\
BHT (Butylated hydroxytoluene) & Sigma-Aldrich, St. Louis, EUA & MKBL3562V \\
Filler particles (BaAlSiO ${ }_{2}$ glass) & Esstech, Essington, USA & TSMP005935 \\
\hline
\end{tabular}

Table 2. Experimental groups.

\begin{tabular}{lcc}
\hline Groups & Pre-polymerization composite temperature & Post-curing method \\
\hline $\mathrm{P}$ & Room temperature & none \\
$\mathrm{P} / \mathrm{M}$ & Room temperature & Microwave $(540 \mathrm{~W} / 5 \mathrm{~min})$ \\
$\mathrm{P} / \mathrm{A}$ & Room temperature & Autoclave $\left(120^{\circ} \mathrm{C} / 15 \mathrm{~min}\right)$ \\
$\mathrm{PH}-\mathrm{P}$ & Preheated $\left(60^{\circ} \mathrm{C}\right)$ & none \\
$\mathrm{PH}-\mathrm{P} / \mathrm{M}$ & Preheated $\left(60^{\circ} \mathrm{C}\right)$ & Microwave $(540 \mathrm{~W} / 5 \mathrm{~min})$ \\
$\mathrm{PH}-\mathrm{P} / \mathrm{A}$ & Preheated $\left(60^{\circ} \mathrm{C}\right)$ & Autoclave $\left(120^{\circ} \mathrm{C} / 15 \mathrm{~min}\right)$ \\
\hline
\end{tabular}




\section{Strength tests}

\section{Diametral tensile strength (DTS) test}

A condensation silicon impression material (Clonage, Angelus) mold was obtained from a stainless steel pattern to produce standardized cylindrical specimens with dimensions of $3.0 \mathrm{~mm}( \pm 0.1 \mathrm{~mm})$ in height and $6.0 \mathrm{~mm}( \pm 0.1 \mathrm{~mm})$ in diameter according to the ADA specification No. 27. ${ }^{34}$ The experimental composite was inserted into the mold, overlaid with a polyester strip, and light polymerized using a LED-curing light (DB-686-lb, COXO, Foshan, China) at $1500 \mathrm{~mW} / \mathrm{cm}^{2}$ for $40 \mathrm{~s}$ applied to the top and bottom surfaces. For preheated experimental groups, the experimental composite was maintained in a digital stove at $60^{\circ} \mathrm{C}^{35}$ for 5 minutes before insertion into the mold. After filling, the mold-containing experimental composite was placed in the stove again for $5 \mathrm{~min}$ and then photocured. The specimens were removed from the mold and post-curing was performed according to the experimental group, either by microwaving (540 W for $5 \mathrm{~min}$ in a water solution) or autoclaving (at $120^{\circ} \mathrm{C}$ for 15 minutes), as described by Soares at al. ${ }^{30}$ The specimens $(\mathrm{n}=10)$ were stored in distilled water at $37^{\circ} \mathrm{C}$ for 24 hours before testing. For testing, the specimens were positioned on a universal testing machine (Instron 5965, Canton, USA) and a crosshead speed of $0.5 \mathrm{~mm} / \mathrm{min}$ was applied at the diametrical surface of samples until fracture. Maximum load was recorded in Newtons (N). The DTS of each sample in $\mathrm{MPa}$ was obtained according to the following formula: $\mathrm{DTS}=2 \mathrm{~F} / \pi \mathrm{dL}$, where $\mathrm{F}$ is the maximum load achieved in the test (in N), $\mathrm{d}$ is the diameter of the specimen $(6.0 \mathrm{~mm})$, and $\mathrm{L}$ is the specimen height $(3.0 \mathrm{~mm})$. Each specimen was measured using a digital caliper (Mitutoyo, Japan) before testing.

\section{Flexural strength (FS) test}

A condensation silicon impression material (Clonage, Angelus) mold was produced from a stainless steel pattern to produce standardized rectangular specimens with dimensions of $25( \pm 0.1) \times 2( \pm 0.1)$ $\times 2 \mathrm{~mm}( \pm 0.1 \mathrm{~mm})$ according to ISO $4049 / 2000^{36}$. The experimental composite was inserted into the mold, overlaid with a polyester strip, and then light polymerized (DB-686-lb, COXO) at 1,500 mW/. $\mathrm{cm}^{2}$.
The light source was positioned at the center of the specimen for $40 \mathrm{~s}$; thereafter, the light source was moved to the section adjacent to the center, overlapping the previous section by half the diameter of the exit window, and irradiated for another $40 \mathrm{~s}$. This procedure was repeated until the entire length of the specimen was irradiated. The other side of the specimen was light-cured in the same manner. Preheating and post-curing were performed as described for DTS tests. The specimens were stored in distilled water at $37^{\circ} \mathrm{C}$ for 24 hours before testing. The specimens were positioned on a three-point bending FS testing apparatus (Instron 5965), with two supports located $20 \mathrm{~mm}$ apart, and tested at a crosshead speed of $0.5 \mathrm{~mm} / \mathrm{min}$. The load at fracture was recorded in $\mathrm{N}$, and the $\mathrm{FS}$ was calculated in $\mathrm{MPa}$ using the following equation: $\mathrm{FS}=3 \mathrm{PL} / 2 \mathrm{wb}^{2}$, where $\mathrm{P}$ is the maximum load at fracture $(\mathrm{N}), \mathrm{L}$ is the distance between the supports $(20 \mathrm{~mm}), \mathrm{w}$ is the specimen thickness, and $b$ is the specimen height. Specimen thickness and height were measured with a digital caliper before testing.

\section{Knoop microhardness (KHN) test}

The specimens $(n=10)$ were produced as described for DTS tests, stored in distilled water at $37^{\circ} \mathrm{C}$ for 24 hours, and then embedded in polystyrene resin cylinders. The cylinders were finished with 600, 1,200, and 2,000 grit silicon-carbide paper (Norton, São Paulo, Brazil) under a constant water stream to produce a smooth and uniform surface and to expose the top of each sample. KHN was determined with a universal indenter (HMV-G 21DT, Shimadzu, Tokyo, Japan) through the application of $50 \mathrm{~g}$ for $30 \mathrm{~s}$. Ten indentations were made on each sample, thus resulting in 50 indentations per group.

\section{Degree of conversion (DC)}

A condensation silicon impression material (Clonage, Angelus) mold was produced from a stainless steel pattern to produce standardized rectangular specimens with dimensions of $10( \pm 0.1) \times 5( \pm 0.1) \times 1 \mathrm{~mm}$ ( $\pm 0.1 \mathrm{~mm})$. The experimental composite was inserted into the mold, overlaid with a polyester strip, and then light-cured (DB-686-lb, COXO) at 1,500 mW/cm² for $40 \mathrm{~s}\left(\right.$ energy $\left.=60 \mathrm{~J} / \mathrm{cm}^{2}\right)$. The DC was evaluated after 
24 hours of storage in a dry and dark container at $37^{\circ} \mathrm{C}$ using Fourier-transform infrared (FTIR) spectroscopy $(n=5)$. Quantitative determination of DC was based on the two-band technique. The DC was assessed using FTIR spectroscopy (Vertex 70, Bruker Optik $\mathrm{GmbH}$, Ettlingen, Germany) with attenuated total reflectance (ATR crystal) sampling and deuterated triglycine sulfate detector elements (Bruker Optik). The spectra were obtained between aromatic $\mathrm{C}=\mathrm{C}$ $\left(1608 \mathrm{~cm}^{-1}\right)$ and aliphatic $\mathrm{C}=\mathrm{C}$ bond stretching vibrations $\left(1,638 \mathrm{~cm}^{-1}\right)$, with a $4 \mathrm{~cm}^{-1}$ resolution and 32 scans. DC was calculated from the equivalent aliphatic $\left(1,638 \mathrm{~cm}^{-1}\right)$ and aromatic $\left(1,608 \mathrm{~cm}^{-1}\right)$ molar ratios of cured (C) and uncured (U) experimental composite specimens according to the following equation: $\mathrm{DC}(\%)=(1-\mathrm{C} / \mathrm{U}) \times 100$.

\section{Scanning electron microscopy (SEM)}

Randomly selected fractured samples from the FS test were subjected to SEM analysis. The fixed samples on metal stubs were sputtered with gold (one cycle of $120 \mathrm{~s}$ ) under vacuum in a sputtering device (Denton Vacuum, Desk V, Moorestown, EUA). The surfaces were analyzed by SEM (JEOL, JSM-6610; Thermo Scientific NSS Spectral Imaging, São Paulo, Brazil), focusing on the fracture features as well as the integrity and homogeneity along the interfaces between the glass fibers and resin matrix.

\section{Statistical analyses}

Data were analyzed using the SPSS 20.0 software (IBM, New York, USA) at an alpha significance level of $5 \%$. In this software, a factorial analysis could be performed using a general linear model (GLM) procedure, thus comparing the following factors under study: preheating at two levels (preheated or not preheated) and post-curing at three levels (not post-cured, microwave post-curing, or autoclave post-curing). If any factor, or the interaction between factors, was significant, complementary tests were performed as follows: data were initially subjected to the Kolmogorov-Smirnov test of normality, which was then followed by one-way ANOVA and Tukey's HSD test (for a significant GLM result for post-curing or for the interaction between factors) or by the independent T-test (for a significant GLM result for preheating). Because the experimental composite was used in previous studies without preheating or post-curing, we considered the absence of these factors as a control group, and then a Dunnett test (two-sided) was used to compare all test groups against the control group and verify if there was any advantage in employing the modified methods.

\section{Results}

Factorial analysis (Table 3) using the GLM procedure showed no significant interaction between factors, no matter which variable was analyzed. Preheating alone had a significant effect on FS $(p=0.0001)$ and KHN ( $p=0.0001)$. Post-curing alone had a significant effect on KHN ( $p=0.0001)$. For DTS and $D C$, no experimental treatment had a significant effect $(p>0.05)$. All results for each variable are explained above.

\section{Diametral tensile strength (DTS)}

The interaction between the factors under study was not significant for DTS ( $p=0.235$ ). Furthermore, each factor alone did not significantly affect DTS. However, the Dunnett test showed that preheating significantly $(\mathrm{p}<0.05)$ increased DTS in relation to the control group (Figure 1).

Table 3. Univariate factorial analysis of variance $(\alpha=0.05)$ for each variable (diametral tensile strength, flexural strength, knoop microhardness, conversion degree) under study.

\begin{tabular}{lcccc}
\hline \multirow{2}{*}{ Factors under study } & \multicolumn{3}{c}{$p$-values } \\
\cline { 2 - 5 } & Diametral tensile strength & Flexural strength & Knoop microhardness & Degree of conversion \\
\hline Preheating & 0.054 & 0.0001 & 0.0001 & 0.478 \\
Post-curing & 0.217 & 0.210 & 0.0001 & 0.310 \\
Interaction & 0.235 & 0.403 & 0.963 & 0.887 \\
\hline
\end{tabular}




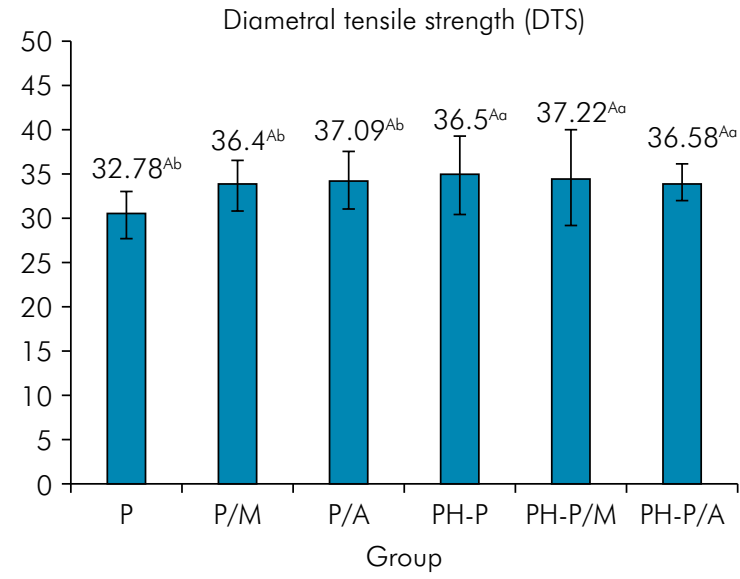

Means (MPa) and standard deviations (vertical bar) are shown. ANOVA comparisons revealed no differences between groups $(p>0.05)$. The Dunnett test revealed that preheating significantly $(p<0.05)$ increased the DTS compared with the control group. Equals capital letters show no statistically significant difference by ANOVA ( $p>0.05)$. Different tiny letter show significant statistically difference by Dunnet test $(p<0.05)$.

Figure 1. Results of the diametral tensile strength test.

\section{Flexural strength (FS)}

Factorial analysis showed that just preheating $(p=0.0001)$ significantly affected FS. T-tests showed that in all pairwise comparisons (Figure 2), the preheated groups had significantly higher FS compared with non-preheated groups $(\mathrm{p}<0.05)$. Finally, the Dunnett test showed that only the preheated groups (all of them) had significantly higher FS than the control group $(\mathrm{p}<0.05)$.

\section{Knoop microhardness KHN}

Factorial analysis of KHN showed that preheating $(p=0.0001)$ and post-curing $(p=0.0001)$ significantly affected KHN; however, the interaction between these factors was not significant $(p=0.963)$. Thus, either preheating or post-curing resulted in high KHN. Pairwise comparisons using T-tests (Figure 3) for the preheating factor showed that $\mathrm{PH}-\mathrm{P}$ yielded higher $\mathrm{KHN}$ than $\mathrm{P}(\mathrm{p}=0.029)$; the same finding was observed for PH-P/A versus P/A $(p=0.048)$ as well as $\mathrm{PH}-\mathrm{P} / \mathrm{M}$ versus $\mathrm{P} / \mathrm{M}(\mathrm{p}=0.049)$. In addition, the mean KHN of all preheated groups (166.32 \pm 48.0$)$ was significantly different $(p=0.001)$ than the mean of all non-preheated groups (146.06 \pm 54.17$)$.

Comparisons of post-curing factors by ANOVA following the Tukey test (Figure 4) showed that $\mathrm{P} / \mathrm{M}$ and $\mathrm{P} / \mathrm{A}$ were similarly effective and both yielded FRCs with higher KHN than $\mathrm{P}(\mathrm{p}=0.08)$; moreover, the effects of $\mathrm{PH}-\mathrm{P} / \mathrm{M}$ and $\mathrm{PH}-\mathrm{P} / \mathrm{A}$ were similar, and both yielded FRCs with higher KHN than PH-P $(p=0.001)$. In addition, the mean $\mathrm{KHN}$ of the $\mathrm{P} / \mathrm{M}$

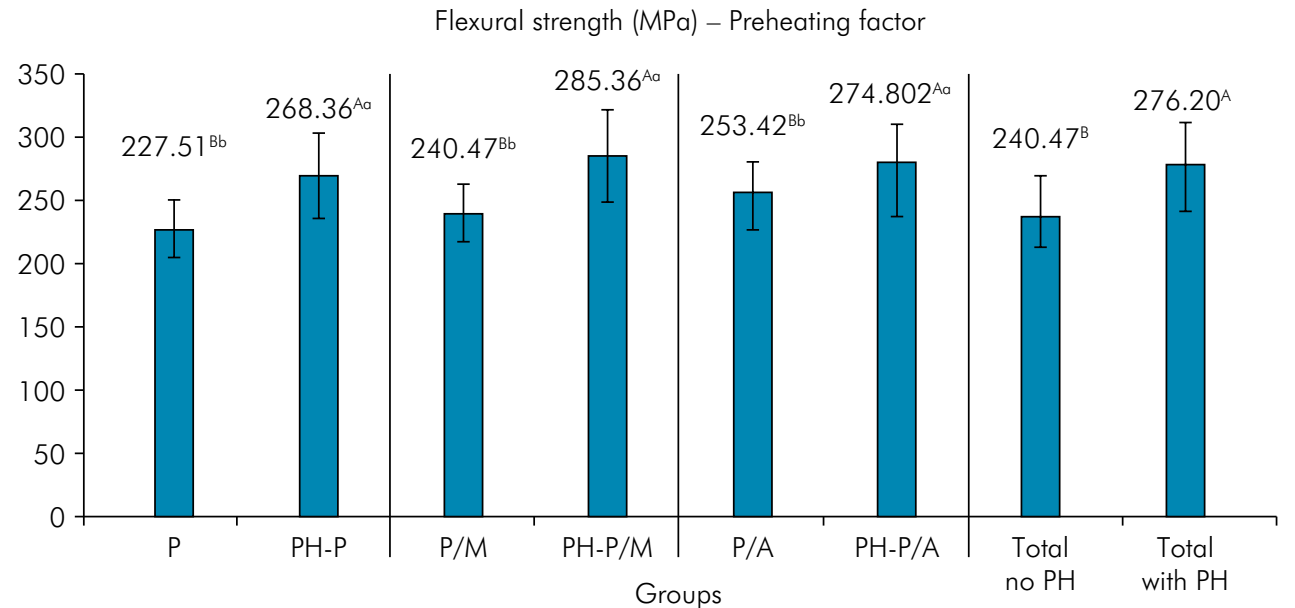

Means (MPa) and standard deviations (vertical bar) are shown. T-tests revealed statistically significant differences between groups that were and were not preheated $(\mathrm{p}<0.05)$ in each column $(\mathrm{P} \times \mathrm{PH}-\mathrm{P}, \mathrm{P} / \mathrm{M} \times \mathrm{PH}-\mathrm{P} / \mathrm{M}, \mathrm{P} / \mathrm{A} \times \mathrm{PH}-\mathrm{P} / \mathrm{A}$, and Total-without $\mathrm{PH} \times \mathrm{Total}$-with $\mathrm{PH})$. The Dunnett test revealed that the preheated groups (all of them) had significantly higher FS than the control group ( $p<0.05)$. Different capital letters show no statistically significant difference by T-Test $(p>0.05)$ between each preheated and not preheated groups. Different tiny letter show statistically significant difference $(p<0.05)$ between preheated groups and control group by Dunnet test.

Figure 2. Flexural strength test results for preheating. 
Knoop Microhardness (KNH) - Preheating factor

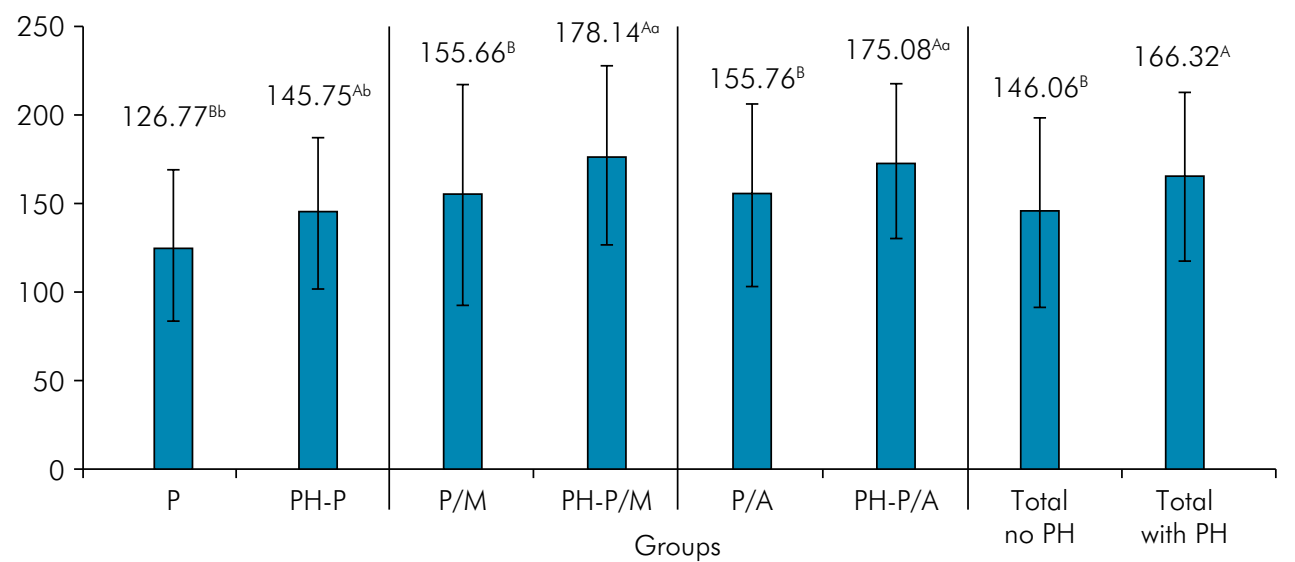

Means (KHN) and standard deviations (vertical bar) are shown. T-tests revealed statistically significant differences between groups that were and were not preheated $(\mathrm{p}<0.05)$ in each column $(\mathrm{P} \times \mathrm{PH}-\mathrm{P}, \mathrm{P} / \mathrm{M} \times \mathrm{PH}-\mathrm{P} / \mathrm{M}, \mathrm{P} / \mathrm{A} \times \mathrm{PH}-\mathrm{P} / \mathrm{A}$ and Total-no $\mathrm{PH} \times$ Total-with $\mathrm{PH})$. The Dunnett test revealed that all groups, except the PH-P group, had significantly higher KHN than the control group $(p<0.05)$. Different capital letters show statistically significant difference by T-Test $(p>0.05)$ between each preheated and not preheated groups. Different tiny lefter show statistically significant difference between preheated groups and control group by Dunnet test.

Figure 3. Results of knoop microhardness for preheating.

$(166.90 \pm 57.42)$ and $\mathrm{P} / \mathrm{A}$ groups $(165.42 \pm 48.92)$ were significantly different $(\mathrm{p}=0.0001)$ than the mean KHN of all P groups $(136.26 \pm 43.61)$.

The Dunnett test revealed that all groups except the PH-P group had significantly higher KHN than the control group $(\mathrm{p}<0.05)$.

\section{Degree of conversion (DC)}

Factorial analysis showed that neither preheating $(p=0.478)$ and post-curing $(p=0.310)$ nor their interaction $(p=0.887)$ significantly affected DC (Figure 5). Moreover, the Dunnett test failed to show any differences in comparison with the control group $(p>0.05)$.

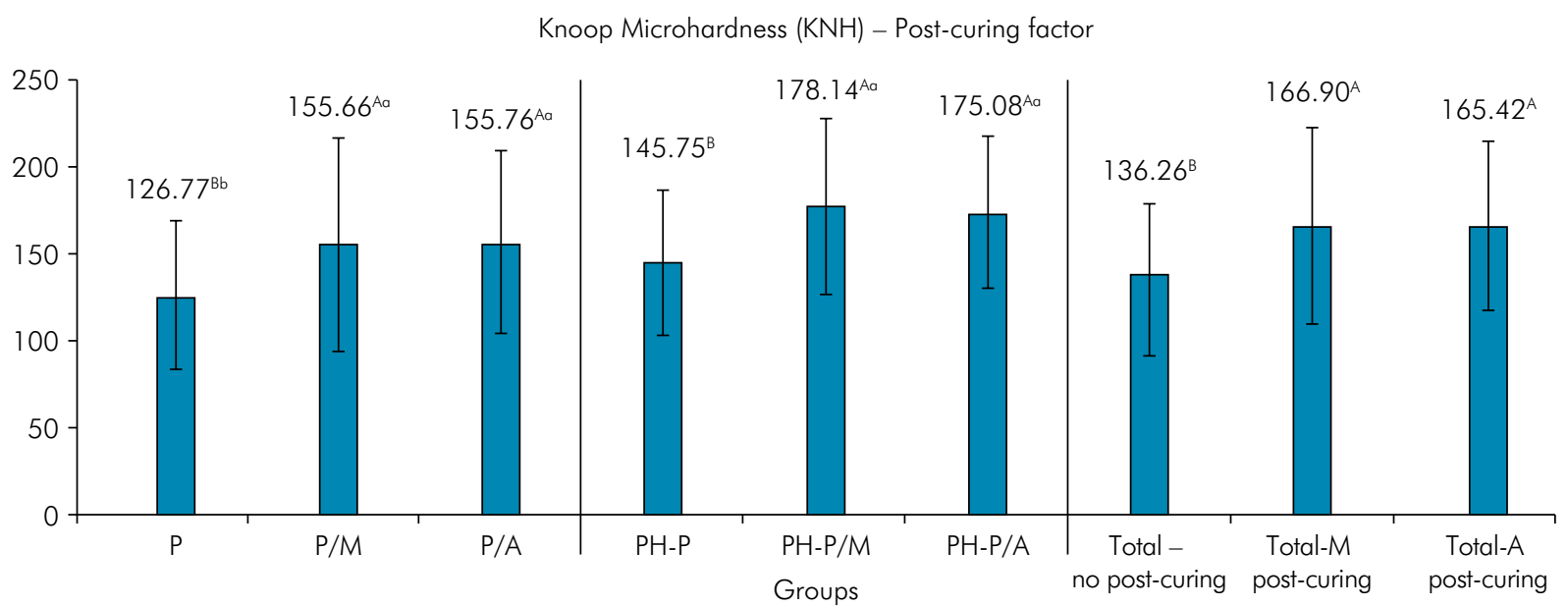

Means (KHN) and standard deviations (vertical bar) are shown. Comparisons for the post-curing factor by ANOVA and Tukey test revealed differences $(p<0.05)$ between groups that were and were not post-cured. The Dunnett test revealed that all post-cured groups had significantly higher KHN than the control group ( $<<0.05)$. Different capital letters show statistically significant difference by ANOVA and Turkey test ( $p<0.05)$ between groups each column. Different tiny letters show statistically significant difference $(p<0.05)$ between between post-cured groups and control group by Dunnet test.

Figure 4. Results of knoop microhardness for post-curing. 


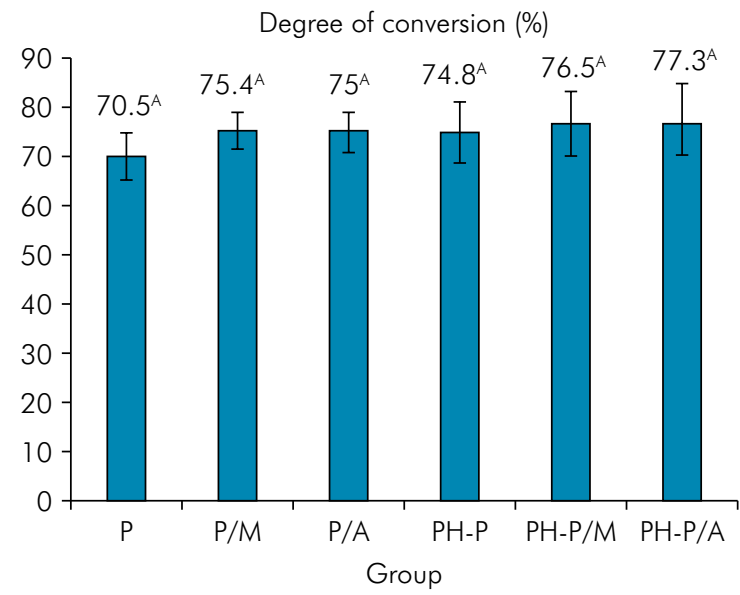

Means (\%) and standard deviations (vertical bar) are shown. ANOVA comparisons revealed no difference between groups $(p>0.05)$. The Dunnett test revealed no differences compared with the control group ( $p>0.05)$. Equals capital letters show no statistically significant difference by ANOVA and Dunnet tests $(p>0.05)$

Figure 5. Degree of conversion results.

\section{Scanning electron microscopy (SEM)}

SEM analysis revealed the interaction between the resin and fibers in the preheated and non-preheated groups. We observed resin remnants at the fiber surface in both groups that were and were not preheated, thus showing good micromechanical interlocking (Figures 6, 7, and 8). However, preheating clearly promoted better micromechanical interlocking and adhesion between the fibers and resin; this can be seen in Figures 6B, 7B, and 8B, which show intimate contact between the fibers and resin.

\section{Discussion}

The use of glass fiber to reinforce dental polymers has been reported in several studies, ${ }^{1,4,10}$ and the development of new strategies is important to simultaneously increase the fiber content and reduce internal flaws, thus leading to improved mechanical properties of these materials. Similar to conventional resin composites, the resin matrix of FRCs is based on Bis-GMA/TEGDMA monomers; consequently, the temperature of the composite before photopolymerization and the use of post-curing methods influence its mechanical properties and DC, mainly owing to the lowered resin matrix viscosity and increased free radical mobility. ${ }^{24,25}$ This study evaluated the effect of preheating and post-curing on DTS, FS, KHN, and DC of an experimental FRC. It was initially hypothesized that preheating and post-curing the FRC could improve its mechanical properties and DC. Overall, the analysis of the factors under study in isolation demonstrated that preheating was significant for improve FS and KHN;
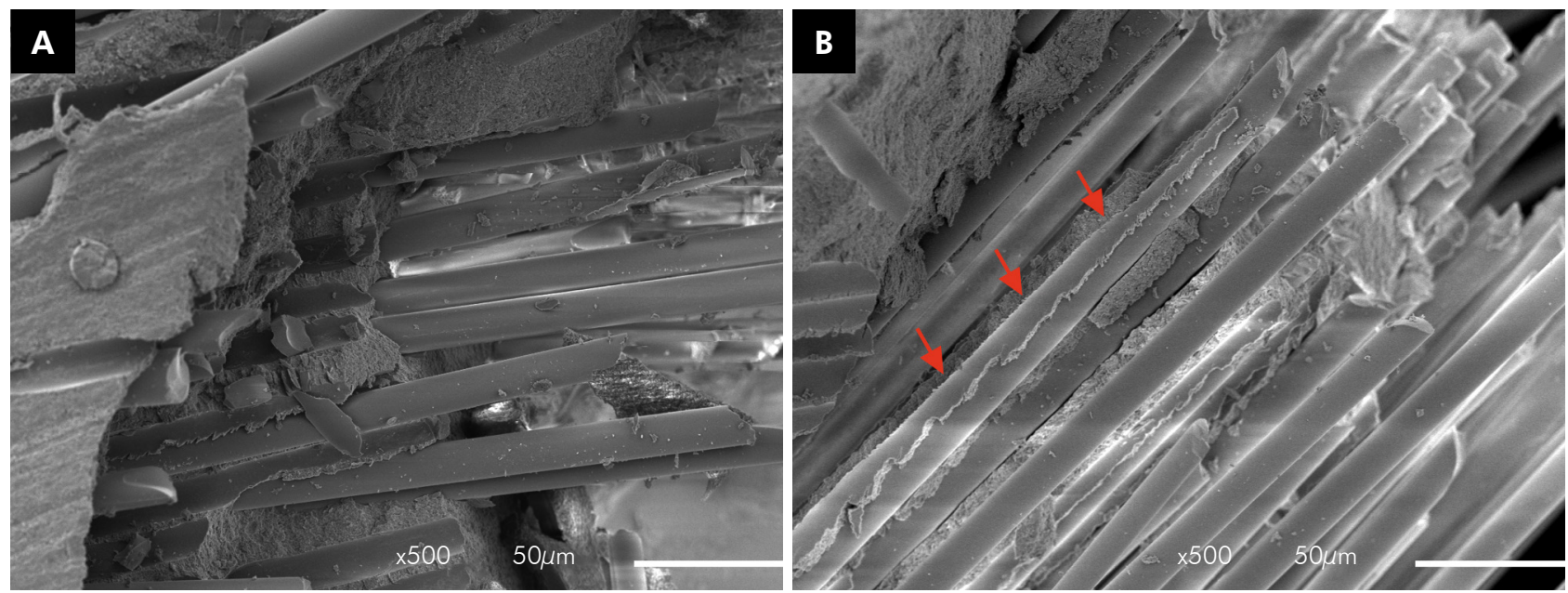

(A) At 500x, the P group revealed some remnants of the resin matrix at the fiber surfaces. (B) At $500 \times$, the PH-P group revealed resins in intimate contact with glass fibers (arrows).

Figure 6. SEM analysis revealing the interaction between the fibers and resin matrix in groups that were or were not preheated. 

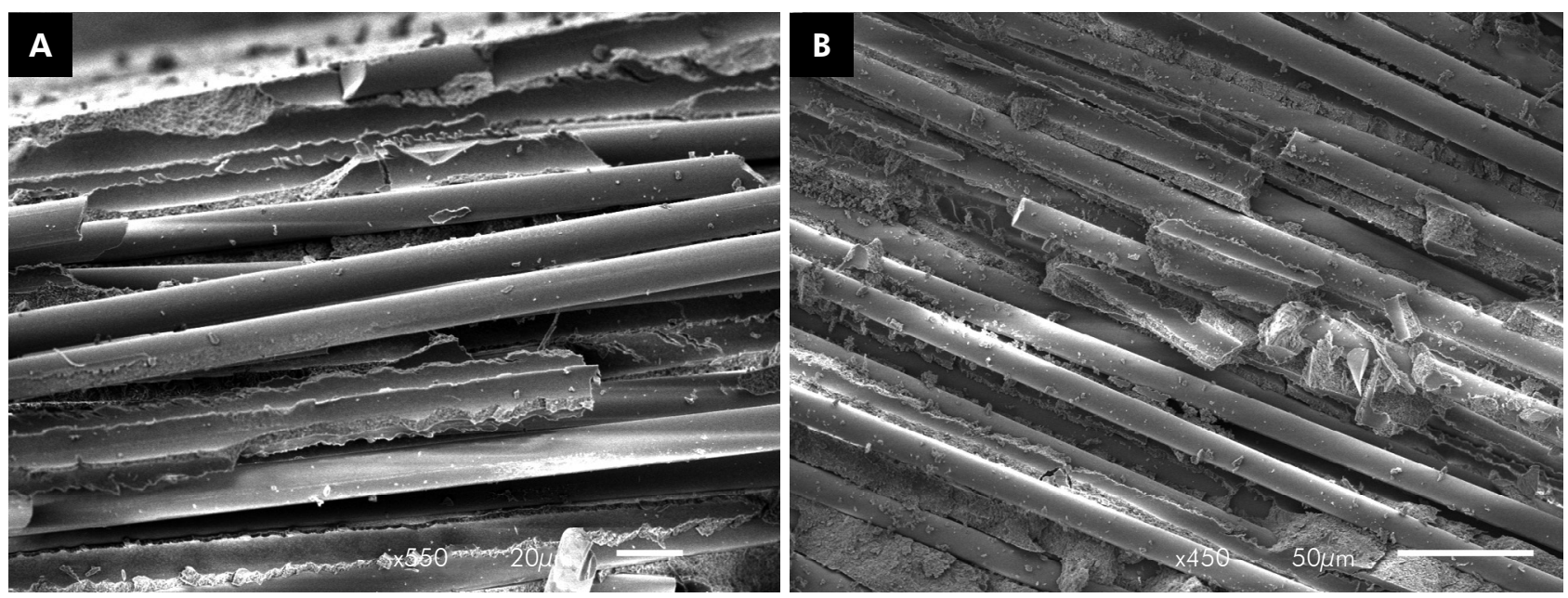

(A) At 530x, few resins remaining at the fiber surfaces were observed in the P/A group. (B) At 450x, the PH-P/A group revealed better interaction between the fibers and resin matrix with lots of remaining resin at the fiber surfaces.

Figure 7. SEM analysis revealing the interaction between the fibers and resin matrix in groups that were or were not preheated.

post-curing was significant just for improved KHN; only; DTS and DC were not affected; by preheating or post-curing; and the interaction between preheating and post-curing did not significant. Consequently, the hypothesis of this study was partially confirmed.

Previous studies demonstrated that increasing the temperature of the resin composite results in higher hardness, DC, and other physical properties ${ }^{21-25}$. Conventional resin composites are generally heated to $68^{\circ} \mathrm{C}$, which is sufficient to decrease their viscosity without causing pulpal damage. ${ }^{23}$ In the present study, preheating at $60^{\circ} \mathrm{C}$ significantly improved the FS and KHN of the FRC; however, DTS and DC were not affected (Table 1). The FRC's lower viscosity enabled easier handling and better adaptation to the specimen molds, thus reducing internal and surface defects and creating better interaction between the resin and fibers, as can be seen in Figures 6, 7 and
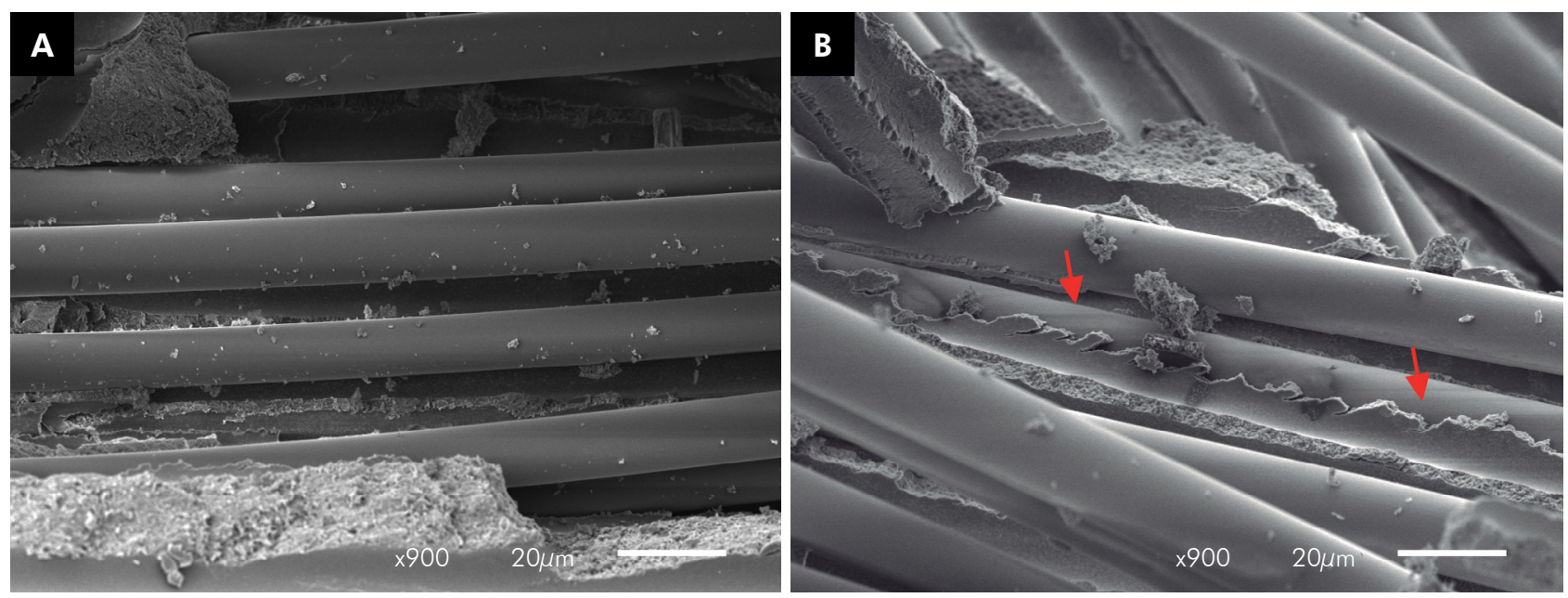

(A) At 900x, the poor interaction between the fibers and resin matrix could be closely examined in the P/M group. (B) At 900 x, the PH-P group showed remnants of resin adhered inwardly to the fiber surfaces (arrows).

Figure 8. SEM analysis revealing the interaction between the fibers and resin matrix in groups that were or were not preheated. 
8. This could explain the effects of preheating on FS and KHN. This is an important finding as preheating can be easily performed by the clinician.

Reduction of internal defects at the resin-fiber interphase after preheating the FRC promotes more homogeneous material with better stress transference between the fibers and resin matrix. ${ }^{19,37}$ Despite the fact that preheating itself did not influence DTS, the cohesive strength of all the tested groups was higher than that of the control group, thus suggesting that both factors are important for this property. Voids around poorly impregnated fibers become foreign bodies in the composite and allow water to infiltrate, thus reducing the cohesive strength and enabling hydrolytic degradation of the resin matrix. ${ }^{37,38}$ The FS was directly affected by preheating the FRC such that only the preheated groups were significantly different from the control group. Specimens used for FS testing are much thinner than those used for DTS testing, and the impact of minimizing voids and better stress distribution probably made preheating critical for this test. In FRCs, areas without fibers are prone to air encapsulation in the resin matrix, ${ }^{11}$ oxygen may also inhibit resin matrix polymerization, thus decreasing the load-bearing capacity of FRC and increasing water sorption, which negatively impacts the composites' mechanical properties. ${ }^{39}$

Preheating and post-curing influenced KHN; however, because the DC was unaffected, it seemed that the factors analyzed in the study promoted a more homogeneous material that yielded a tough polymer, probably with more cross-linked monomers. ${ }^{40} \mathrm{~A}$ correlation between monomer conversion and KHN has been reported previously; ${ }^{26,41}$ however, it is also known that a high DC is not always observed in highly cross-linked polymers ${ }^{42}$. Values of DC in the range of $55 \%-75 \%$ have been reported for conventional and experimental dimethacrylate-based resin composites. ${ }^{42,43}$ Previously. ${ }^{44}$ FRCs in a dimethacrylate resin system showed DC values in the range of $69 \%-72 \%$, similar to those observed in this study.

The high-energy density during light-curing $\left(60 \mathrm{~J} / \mathrm{cm}^{2}\right)$ used here was far beyond the minimum necessary $\left(16 \mathrm{~J} / \mathrm{cm}^{2}\right)^{20}$ for light-cured composites; this may also explain the non-significant effect of preheating or post-curing on DC in this study. The high-energy density associated with preheating at $60^{\circ} \mathrm{C}$ increased FS and KHN. Post-curing after irradiation is also effective for improving some mechanical properties and the DC of composites. . $^{30,31,32,33}$ Soares et al. ${ }^{30}$ reported that post-curing in an autoclave, oven, and microwave increases the DTS and KHN of direct resin composites. Post-curing with additional heating results in higher amplitude of segmental chain vibration, thus allowing near-radical and methacrylate groups to collide, thus increasing the monomer conversion and mechanical properties of the composites. ${ }^{30,33}$ The influence of post-curing methods depends on the composition of the resin composite. ${ }^{26}$ The present results demonstrated that post-curing methods with an autoclave or microwave heating promoted a significant increase only in the $\mathrm{KHN}$ of the FRC. This finding is in accordance with those reported in previous studies. ${ }^{30,33}$ For restorations using FRC, KHN is an important factor in the clinical behavior of the composition. Studies have shown that even for FRCs exhibiting acceptable mechanical properties, clinical problems were related to surface roughness and wear resistance. ${ }^{45,46}$ Improvements in KHN with preheating and post-curing can probably promote better performance in this area; however, this should be further evaluated in future studies.

The FS test has been widely used to characterize the mechanical properties of restorative dental materials. FS was the mechanical property selected by the International Standards Organization for screening resin-based filling materials (ISO 2009) and was considered a discriminatory and sensitive test for subtle changes in a material's substructure. ${ }^{47}$ The FS is directly correlated with the fiber/matrix ratio. Structural defects, such as bubbles and discontinuities along the interface between the matrix and the fibers, influence the FS of FRC posts. ${ }^{48}$ In a previous study, Garoushi, Vallittu, and Lassila ${ }^{7}$ used a similar composite with $22.5 \mathrm{wt} \%$ of 3-mm glass fibers and obtained a FS of $211 \mathrm{MPa}$. Recently, a FS of $259.91 \mathrm{MPa}$ was achieved after increasing the fiber content up to $30 \mathrm{wt} \%{ }^{10}$ The high fiber content in a polymer matrix leads to a significant increase in the mechanical properties of polymer-based materials. Posts with a higher fiber/matrix resin ratio are expected to have greater fracture resistance, ${ }^{48,49}$ however, if the adhesion 
between glass fiber and matrix resin is enhanced, better mechanical properties can be achieved. The bonding between the resinous matrix and fibers is one of the most important factors that may influence the post strength..$^{50}$ In the present study, the same FRC when subjected to preheating and post-curing in a microwave, yielded a FS of 285.36 MPa. Preheating significantly affected FS, probably owing to the better interaction between the fibers and resin and fewer internal flaws.

The DTS test provides information on bulk properties and is widely used to measure the tensile strength of elastic and brittle materials. ${ }^{51}$ The sample format $(\varnothing 3 \times 6 \mathrm{~mm})$ favors the random distribution of fibers in the resin matrix, thus enabling cohesive evaluation of the FRC. Conversely, the FS samples do not enable fibers to enter into either a full multi-directional or unidirectional arrangement owing to the FS parameters of the ISO standard $(2 \times 2 \times 25 \mathrm{~mm}$; width $\times$ thickness $\times$ length). These parameters tend to align the fibers. These differences in the tests may explain the discrepancies in our study results.

\section{References}

1. Garoushi S, Gargoum A, Vallittu PK, Lassila L. Short fiber-reinforced composite restorations: A review of the current literature. J Investig Clin Dent. 2018 Feb 25. https://doi.org/10.1111/jicd.12330

2. Wang HW, Chang YH, Lin CL. A novel anatomical short glass fiber reinforced post in an endodontically treated premolar mechanical resistance evaluation using acoustic emission under fatigue testing. J Mech Behav Biomed Mater. 2017 Jan;65:151-9. https://doi.org/10.1016/i.jmbbm.2016.08.018

3. Özcan M, Koekoek W, Pekkan G. Load-bearing capacity of indirect inlay-retained fixed dental prostheses made of particulate filler composite alone or reinforced with E-glass fibers impregnated with various monomers. J Mech Behav Biomed Mater. 2012 Aug;12:160-7. https://doi.org/10.1016/i.jmbbm.2012.02.023

4. Garoushi S, Vallittu PK, Lassila LV. Direct restoration of severely damaged incisors using short fiber-reinforced composite resin. J Dent. 2007 Sep;35(9):731-6. https://doi.org/10.1016/i.jdent.2007.05.009

5. Garoushi S, Vallittu PK, Lassila LV. Continuous and short fiber reinforced composite in root post-core system of severely
Poor impregnation of fibers with the resin matrix decreases the load-bearing capacity of the FRCs. ${ }^{10,38}$ Therefore, to act as a crack stopper, adhesion of the fiber to the resin is crucial. This study showed that preheating was important to increase the interaction between the glass fibers and methacrylate monomers. Despite this, our experimental FRC is difficult to manipulate owing to its high fiber content. Future studies should focus on the monomer composition by using different monomers to decrease the viscosity; this could help enable better handling and could probably enhance the DC and other mechanical properties.

\section{Conclusions}

Thus, is possible to conclude that preheating and post-curing methods have unique influences on different mechanical properties of FRCs. Preheating improved the FS and KHN, whereas post-curing improved the KHN. Preheating and post-curing methods can thus be used to increase selected mechanical properties of FRCs.

damaged incisors. Open Dent J. 2009 Mar;3(1):36-41. https://doi.org/10.2174/1874210600903010036

6. Bijelic J, Garoushi S, Vallittu PK, Lassila LV. Fracture load of tooth restored with fiber post and experimental short fiber composite. Open Dent J. 2011 Mar;5(1):58-65. https://doi.org/10.2174/1874210601105010058

7. Bijelic J, Garoushi S, Vallittu PK, Lassila LV. Short fiber reinforced composite in restoring severely damaged incisors. Acta Odontol Scand. 2013 Sep;71(5):1221-31. https://doi.org/10.3109/00016357.2012.757640

8. Acharya S, Tandon S. Fiber-reinforced composites as a fixed space maintainer in case of primary tooth loss. Compend Contin Educ Dent. 2011 Jul-Aug;32(6):E104-5.

9. Garoushi S, Vallittu PK, Lassila LV. Short glass fiber reinforced restorative composite resin with semi-inter penetrating polymer network matrix. Dent Mater. 2007 Nov;23(11):1356-62. https://doi.org/10.1016/i.dental.2006.11.017

10. Garoushi S, Säilynoja E, Vallittu PK, Lassila L. Physical properties and depth of cure of a new short fiber reinforced composite. Dent Mater. 2013 Aug;29(8):835-41. https://doi.org/10.1016/j.dental.2013.04.016 
11. Fonseca RB, Almeida LN, Mendes GA, Kasuya AV, Favarão IN, Paula MS. Effect of short glass fiber/filler particle proportion on flexural and diametral tensile strength of a novel fiber-reinforced composite. J Prosthodont Res. 2016 Jan;60(1):47-53. https://doi.org/10.1016/i.jpor.2015.10.004

12. Lassila L, Garoushi S, Vallittu PK, Säilynoja E. Mechanical properties of fiber reinforced restorative composite with two distinguished fiber length distribution. J Mech Behav Biomed Mater. 2016 Jul;60:331-8. https://doi.org/10.1016/i.jmbbm.2016.01.036

13. Garoushi SK, Lassila LV, Vallittu PK. Short fiber reinforced composite: the effect of fiber length and volume fraction. J Contemp Dent Pract. 2006 Nov;7(5):10-7.

14. Dyer SR, Lassila LV, Jokinen M, Vallittu PK. Effect of fiber position and orientation on fracture load of fiber-reinforced composite. Dent Mater. 2004 Dec;20(10):947-55. https://doi.org/10.1016/i.dental.2003.12.003

15. Fonseca RB, Paula MS. Favarão IN, Kasuya AVB, Almeida LN, Mendes GAM, Carlo HL. Reinforcement of dental methacrylate with glass fiber after heated silane application. BioMed Res Int. 2014;2014:1-5.

16. Matinlinna JP, Lung CY, Tsoi JK. Silane adhesion mechanism in dental applications and surface treatments: A review. Dent Mater. 2018 Jan;34(1):13-28. https://doi.org/10.1016/j.dental.2017.09.002

17. Vallittu PK. The effect of void space and polymerization time on transverse strength of acrylic-glass fibre composite. J Oral Rehabil. 1995 Apr;22(4):257-61. https://doi.org/10.1111/j.1365-2842.1995.tb00083.x

18. Vallittu PK. High-aspect ratio fillers: fiber-reinforced composites and their anisotropic properties. Dent Mater. 2015 Jan;31 (1):1-7. https://doi.org/10.1016/i.dental.2014.07.009

19. Lassila L, Keulemans F, Säilynoja E, Vallittu PK, Garoushi S. Mechanical properties and fracture behavior of flowable fiber reinforced composite restorations. Dent Mater. 2018 Apr;34(4):598-606. https://doi.org/10.1016/i.dental.2018.01.002

20. Peutzfeldt A, Asmussen E. Resin composite properties and energy density of light cure. J Dent Res. 2005 Jul;84(7):659-62. https://doi.org/10.1177/154405910508400715

21. Fróes-Salgado NR, Silva LM, Kawano Y, Francci C, Reis A, Loguercio AD. Composite pre-heating: effects on marginal adaptation, degree of conversion and mechanical properties. Dent Mater. 2010 Sep;26(9):908-14. https://doi.org/10.1016/i.dental.2010.03.023

22. Lohbaver U, Zinelis S, Rahiotis C, Petschelt A, Eliades $G$. The effect of resin composite pre-heating on monomer conversion and polymerization shrinkage. Dent Mater. 2009 Apr;25(4):514-9. https://doi.org/10.1016/i.dental.2008.10.006

23. Ayub KV, Santos GC Jr, Rizkalla AS, Bohay R, Pegoraro $\mathrm{LF}$, Rubo JH et al. Effect of preheating on microhardness and viscosity of 4 resin composites. J Can Dent Assoc. 2014;80(12):e12.
24. Daronch M, Rueggeberg FA, Goes MF. Monomer conversion of pre-heated composite. J Dent Res. 2005 Jul;84(7):663-7. https://doi.org/10.1177/154405910508400716

25. Lovell LG, Lu H, Elliott JE, Stansbury JW, Bowman CN. The effect of cure rate on the mechanical properties of dental resins. Dent Mater. 2001 Nov;17(6):504-11. https://doi.org/10.1016/S0109-5641(01)00010-0

26. Rueggeberg FA, Giannini M, Arrais CAG, Price RBT. Light curing in dentistry and clinical implications: a literature review. Braz Oral Res. 2017 Aug;31(31 suppl 1):e61. https://doi.org/10.1590/1807-3107bor-2017.vol31.0061

27. Högg C, Maier M, Dettinger-Maier K, He X, Rothmund L, Kehe $\mathrm{K}$ et al. Effect of various light curing times on the elution of composite components. Clin Oral Investig. 2016 Nov;20(8):2113-21. https://doi.org/10.1007/s00784-015-1698-7

28. Fonseca AS, Moreira ADL, Albuquerque PP, Menezes LR, Pfeifer CS, Schneider LF. Effect of monomer type on the CC degree of conversion, water sorption and solubility, and color stability of model dental composites. Dent Mater. 2017 Apr;33(4):394-401. https://doi.org/10.1016/i.dental.2017.01.010

29. Al Sunbul H, Silikas N, Watts DC; SunBul H. Polymerization shrinkage kinetics and shrinkage-stress in dental resin-composites. Dent Mater. 2016 Aug;32(8):998-1006. https://doi.org/10.1016/i.dental.2016.05.006

30. Soares CJ, Pizi EC, Fonseca RB, Martins LR. Mechanical properties of light-cured composites polymerized with several additional post-curing methods. Oper Dent. 2005 May-Jun;30(3):389-94.

31. Park SH, Lee CS. The difference in degree of conversion between light-cured and additional heat-cured composites. Oper Dent. 1996 Sep-Oct;21(5):213-7.

32. Silva GR, Simamoto-Júnior PC, Mota AS, Soares CJ. Mechanical properties of light-curing composites polymerized with different laboratory photo-curing units. Dent Mater J. 2007 Mar;26(2):217-23. https://doi.org/10.4012/dmj.26.217

33. Peutzfeldt A, Asmussen E. The effect of postcuring on quantity of remaining double bonds, mechanical properties, and in vitro wear of two resin composites. J Dent. 2000 Aug;28(6):447-52. https://doi.org/10.1016/S0300-5712(00)00021-X

34. American National Standard Institute, American Dental Association. Specification No 27. Resin-based filling materials. Chicago, III: American Dental Association; 1993.

35. Daronch M, Rueggeberg FA, Moss L, Goes MF. Clinically relevant issues related to preheating composites. J Esthet Restor Dent. 2006;18(6):340-50. https://doi.org/10.1111/j.1708-8240.2006.00046.x

36. International Organization for Standardization. Specification $N^{\circ}$ 4049. Dentistry - polymer-based filling, restorative and luting materials. Geneva: International Organization for Standardization; 2009. 
37. Behr M, Rosentritt M, Lang R, Handel G. Flexural properties of fiber reinforced composite using a vacuum/pressure or a manual adaptation manufacturing process. J Dent. 2000 Sep;28(7):509-14. https://doi.org/10.1016/S0300-5712(00)00031-2

38. Vallittu PK. Oxygen inhibition of autopolymerization of polymethylmethacrylate-glass fibre composite. J Mater Sci Mater Med. 1997 Aug;8(8):489-92. https://doi.org/10.1023/A:1018578210453

39. Garoushi S, Lassila LV, Tezvergil A, Vallittu PK. Load bearing capacity of fibre-reinforced and particulate filler composite resin combination. J Dent. 2006 Mar;34(3):179-84. https://doi.org/10.1016/i.jdent.2005.05.010

40. Al-Zain AO, Ecxert GJ, Lukic H, Megremis SJ, Platt JA. Degree of conversion and cross-link density within a resin-matrix composite. J Biomed Mater Res B Appl Biomater. 2018 May;106(4):1496-504. https://doi.org/10.1002/ibm.b.33960

41. Yan YL, Kim YK, Kim KH, Kwon TY. Changes in degree of conversion and microhardness of dental resin cements. Oper Dent. 2010 Mar-Apr;35(2):203-10. https://doi.org/10.2341/09-174-L

42. Gonçalves L, Boaro LC, Miyazaki CL, Kawano Y, Braga RR. Influence of polymeric matrix on the physical and chemical properties of experimental composites. Braz Oral Res. 2015;29(1):e128. https://doi.org/10.1590/1807-3107BOR-2015.vol29.0128

43. Cacciafesta V, Sfondrini MF, Lena A, Scribante A, Vallittu PK, Lassila LV. Flexural strengths of fiber-reinforced composites polymerized with conventional light-curing and additional postcuring. Am
J Orthod Dentofacial Orthop. 2007 Oct;132(4):524-7. https://doi.org/10.1016/i.ajodo.2005.09.036

44. Fagundes TC, Barata TJ, Carvalho CA, Franco EB, Dijken JW, Navarro MF. Clinical evaluation of two packable posterior composites: a five-year follow-up. J Am Dent Assoc. 2009 Apr;140(4):447-54. https://doi.org/10.14219/jada.archive.2009.0194

45. Dijken JW, Sunnegårdh-Grönberg K. Fiber-reinforced packable resin composites in Class II cavities. J Dent. 2006 Nov;34(10):763-9. https://doi.org/10.1016/i.jdent.2006.02.003

46. Yap AU, Teoh SH. Comparison of flexural properties of composite restoratives using the ISO and mini-flexural tests. J Oral Rehabil. 2003 Feb;30(2):171-7. https://doi.org/10.1046/i.1365-2842.2003.01004.x

47. Novais VR, Rodrigues RB. Simamoto-Júnior PC, Correr-Sobrinho L, Soares CJ. Correlation between the Mechanical Properties and Structural Characteristics of Different Fiber Posts System. Braz Dent J. 2016;27(1):46-51. https://doi.org/10.1590/0103-6440201600377

48. Novais VR, Versluis A, Correr-Sobrinho L, Soares CJ. Three-point bending testing of fibre posts: critical analysis by finite element analysis. Int Endod J. 2011 Jun;44(6):519-24. https://doi.org/10.1111/j.1365-2591.2011.01856.x

49. Galhano GA, Valandro LF, Melo RM, Scotti R, Bottino MA. Evaluation of the flexural strength of carbon fiber-, quartz fiber-, and glass fiber-based posts. J Endod. 2005 Mar;31(3):209-11. https://doi.org/10.1097/01.don.0000137652.49748.0c

50. Huang SH, Lin LS, Fok AS, Lin CP. Diametral compression test with composite disk for dentin bond strength measurement: finite element analysis. Dent Mater. 2012 Oct;28(10):1098-104. 